\title{
QUADRATIC INTERPOLATION OF THE HEINZ MEANS
}

\section{Fuad Kittaneh, Mohammad Sal Moslehian and Mohammad Sababheh}

\begin{abstract}
The main goal of this article is to present several quadratic refinements and reverses of the well known Heinz inequality, for numbers and matrices, where the refining term is a quadratic function in the mean parameters. The proposed idea introduces a new approach to these inequalities, where polynomial interpolation of the Heinz function plays a major role. As a consequence, we obtain a new proof of the celebrated Heron-Heinz inequality proved by Bhatia, then we study an optimization problem to find the best possible refinement. As applications, we present matrix versions including unitarily invariant norms, trace and determinant versions.
\end{abstract}

Mathematics subject classification (2010): 15A39, 15B48, 47A30, 47A63.

Keywords and phrases: Positive matrices, matrix means, norm inequalities, Heinz means.

\section{REFERENCES}

[1] M. Bakherad And M. S. Moslehian, Reverses and variations of Heinz inequality, Linear Multilinear Algebra 63, 10 (2015), 1972-1980.

[2] R. BHATIA, Interpolating the arithmetic-geometric mean inequality and its operator version, Linear Algebra Appl. 413 (2006), 355-363.

[3] J. BouRIN, Some inequalities for norms on matrices and operators, Linear Algebra Appl. 292 (1999), $139-154$.

[4] C. Conde, Young type inequalities for positive operators, Ann. Funct. Anal. 4 (2013), no. 2, 144-152.

[5] R. BHATIA AND C. DAVIS, More matrix forms of the arithmetic-geometric mean inequality, SIAM J. Matrix Anal. 14 (1993), 132-136.

[6] R. Kaur, M. S. Moslehian, M. Singh And C. Conde, Further refinements of the Heinz inequality, Linear Algebra Appl. 447 (2014), 26-37.

[7] R. Kaur AND M. Singh, Complete interpolation of matrix versions of Heron and Heinz means, Math. Inequal. Appl. 16 (2013), 93-99.

[8] F. Kittaneh and Y. ManasRah, Reverse Young and Heinz inequalities for matrices, Linear Multilinear Algebra 59 (2011), 1031-1037.

[9] F. Kittaneh and Y. Manasrah, Improved Young and Heinz inequalities for matrices, J. Math. Anal. Appl. 36 (2010), 262-269.

[10] F. Kittaneh, On the convexity of the Heinz mean, Integral Equations Operator Theory 68 (2010), 519-527.

[11] F. Kittaneh, Norm inequalities for fractional powers of positive operators, Lett. Math. Phys. 27 (1993), 279-285.

[12] F. Kittaneh, M. KRnić, Refined Heinz operator inequalities, Linear and Multilinear Algebra 61 (2013), 1148-1157.

[13] M. KRnIĆ, More accurate Young, Heinz, and Hölder inequalities, Period. Math. Hung. 71 (2015), $78-91$.

[14] M. SingH, Inequalities involving eigenvalues for difference of Operator means, Electron. J. Linear Algebra 27 (2014), 557-568.

[15] M. SABABHEH, Integral inequalities of the Heinz means as convex functions, J. Math. Inequal. 10, 2 (2016), 313-325.

[16] M. SABABHEH, Log and Harmonically log-convex functions related to matrix norms, Oper. Matrices 10, 2 (2016), 453-465. 
[17] M. SABAвHeH, Piecewise quadratic interpolation and applications to the Young inequality, Results in Mathematics 72 (2017), 1315-1328. DOI 10.1007/s00025-016-0636-6.

[18] M. Sababheh And M.S. Moslehian, Advanced refinements of Young and Heinz inequalities, J. Number Theory 172 (2017), 178-199.

[19] L. Zou, Inequalities related to Heinz and Heron means, J. Math. Inequal. 7, 3 (2013), 389-397. 